\title{
To Perform the Higher Education Institution Information System Solution by Combining FLOSS and Custom Development Software
}

\author{
Mujiono Sadikin* \\ Faculty of Computer Science, Universitas Mercu Buana, Jl. Meruya Selatan No. 1, Jakarta Barat, Indonesia. \\ * Corresponding author. Tel.: +62215840816; email: mujiono.sadikin@mercubuana.ac.id \\ Manuscript submitted October 12, 2015; accepted December 15, 2015. \\ doi: 10.17706/ijeeee.2016.6.1.46-55
}

\begin{abstract}
Faced with the very rapid growth of information technology, particularly in software aspect, and its responsibilities to full fill the user need effectively, Higher Education IT Division has to select the best application solution for its institutions. There is an abundant application solution in the market can be chosen. The variations of those solutions are not only on their functionalities, but also on their platform, development tools, and proprietary/free license as well. This paper presents the practical case of application selection and its implementation to Higher Education Institutions environments. Based on internal consideration such: university and user needs, IT staff capabilities and external consideration include software functionalities, software platform etc., it is chosen to combine the solution that combining the software developed internally and FLOSS implementation. By combining these solutions, University able to achieve many benefits such: the suitable with user need, the speed of the implementation process, and the improvement of IT staff skill.
\end{abstract}

Key words: Education information, free license open source software, system higher education institution.

\section{Introduction}

Information technology management is the continuous process includes planning, development, running, and monitoring. In the COBIT frameworks, those domain process are mapped into four domain processes: Plan and Organize (PO), Acquisition and Implementation (AI), Delivery and Support (DS), and Monitoring and Evaluation (ME) [1]. By utilizing the COBIT frameworks, we perform a study and practical implementation of IT Governance in a Higher Education institution. Those study chain are started with IT Governance assessment which its result is presented in [2]. One of the first study results is the recommendation to provide an Information Strategic plan. The study and results in providing the IS strategic plan are summarized in [3].

This paper discusses the execution of activities which are recommended by those previous studies[2], [3]. Whereas all of the activities performed in previous studies are the steps in the PO domain process, the activities in this study are IS management phase included in the AI domain process. In the AI domain process it has to be considered many aspects in IT project management, such as: the source of information system solution, the model of developments, the typical of selected software regarding to its licensing models, etc. There are so many sides of information technology acquisition and implementation that can be discussed while the space is limited, this paper presents only the results of free license opensource software 
(FLOSS) implementation that is combined with custom development to fulfill users need in supporting them to operate daily activities in the higher education environment. As the continuities of the previous study, we implement the AI domain process at the University of Mercu Buana as a case study. The brief explanation regarding the university can be referred in paper [3].

The rest of the paper is organized as bellows: the second section will describe related study regarding to FLOSS aspects such: the beneficial, the case study, etc; the methodology framework of this practical experiments are explained in the section 3; user requirement as the foundation of the application software implementation will be described in section 4; whereas section 5 discuss the list of implemented solution both custom (internal) development and FLOSS; conclusion, in section 6, explain the aspect to which we has to concern in FLOSS implementation; appendix, in the last of this paper, shows some brief explanation related to application software has been operating.

\section{Free License Open Source Software}

FLOSS initiative has become a massive movement in all life areas, especially in the education sectors. With the implementation of FLOSS education institution can take many advantages in technical and commercial aspects as well. These technical benefits aspects such: the ability to customize, its reliability/availability, its performance, and security; whereas the commercial aspects includes: total cost ownerships and cost efficiency [4]. FLOSS also provides a freedom, flexibility and control to the instructor; give freedom and accessibility to the students; increases learning opportunity[5]; and opens unlimited opportunities to developers or students to enhance their skill and capabilities[6]. GNU Operating System Projects [7] claim that there are at least six strong reasons why the educational institution should use FLOSS. These six reasons include: sharing knowledge and tools between communities, independence from any commercial interests, the application of social responsibility in preparing their students to participate in a free digital society in the future, learning in the freedom environment, cost saving, and the stability.

There are plenty successful case studies regarding the implementation of FLOSS for educational environments. The prime example shows that FLOSS is a valid choice is The Open University (OU) in the UK. The university implemented Moodle as a solution for their virtual learning environment, Among the other choices, it is shown that the most suitable information system solution for a Virtual Learning Environment is Moodle [8]. The survey was reported by [9] shows the results that almost of 310 universities across various countries such Argentina, Bulgaria, Brazil, China, Croatia, India, Malaysia and South Africa implement FLOSS (Free/Libre Open Source Software) although only less than a half of them develop FLOSS by themselves. The Computing Campus Project, [10] presents the result of its survey in various universities regarding to the penetration of FLOSS. The survey shows that the FLOSS plays an important role of IT strategy in those campuses. Those campuses expected that FLOSS offer viable for key campuses, administrative application tools such as ERP and financial system. The other report as published by The Alliance for Higher Education Competitiveness, Inc[11] shows that $57 \%$ of the Universities of USA implement some sort of free software in its platform software (operating system, web server, databases, etc.). The proportion of institutions that have not yet consider to implement open source applications is $32 \%$, which $25 \%$ of them use free software. The other study by Arslan M. Oguz, [12] concludes that FLOSS has public good properties as non-excludability and non-rivalry. That's why the increasing of the provision of FLOSS locally or globally will enhance social welfare without any efficiency loss and as one of the most practical areas of FLOSS, educational FLOSS will provide large-scale benefits as seen in some countries.

FLOSS growth increase day by day. Currently, more than 100.000 FLOSS can be downloaded from the internet. The functionality of those FLOSS is very wide ranging, from software platform (OS, databases, web server), development tools (python, R, Perl, etc.) to various specific or general applications. As there are 
many choices of FLOSS, the selection of suitable FLOSS to Higher Education institution is a big challenge. Fortunately, there are some studies that provide a list of FLOSS for educational environment. In [13], Coll et al. list various FLOSS for various education need/function such: education platform, general office, math, image editor, and electronic engineering. Whereas in [14], it is published the list of educational FLOSS. In this report, it can be found plenty choices of FLOSS for many application purposes such: office productivity, graphics, publishing, multimedia, scientific, math, human language, computer programming, educational games, computer infrastructure, information system solution, and primary school children. Moodle is the most popular FLOSS for e-learning application, but there are many other virtual learning tools such as Web CT, Desire2Learn and Black Board [8].

\section{Methodology}

The methodological framework of the application solution implementation consists of 5 main steps: internal assessment (corporate-user need, internal IT condition), solution sources assessment, application selection, implementation-operation-maintenance, and monitoring-evaluation as illustrated in Fig. 1. In the internal assessment stage it is assessed and considered the results of the corporate need analysis and IT condition. These corporate needs have to be used as basic foundation are: university goals, strategic plan, budgeting policy, regulation comply and the other strategic aspects. Whereas the user need is more technical aspects regarding to process business, functionality, reporting, and user capabilities etc. Base on the first steps, we do a solution source assessment to analyze some aspects of application implementations such: implementations model, their platform, its communities if the application is FLOSS, and the cost as well if these applications are proprietary. The two next steps are to make decisions in solution selection and implementation of the decision. In the last step, it is done monitoring and evaluation of all of those steps regarding to their process and results. The output of monitoring and evaluation process will become feedback to the stages cycles.

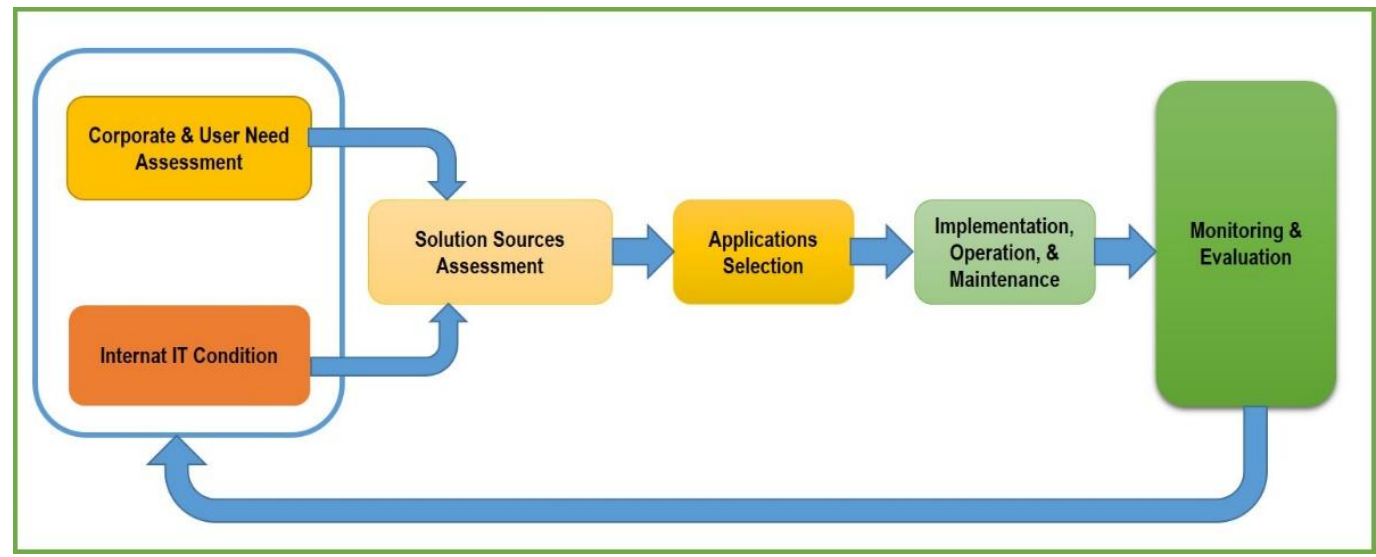

Fig. 1. University application solution implementation method.

\section{User Requirement Analysis}

As is described in the previous section, the FLOSS implementation case study is applied in Universitas Mercu Buana, a private higher education institution located in Jakarta Indonesia. This section explains the university process business, user profiles and IS architecture as the most related components to be discussed for the combination of internal development and FLOSS implementation.

\subsection{Process Business}


The main university's activities are: enrollment, researches, and public/citizen services. To support these main activities, the university provides some supporting activities includes: financial, logistics procurements, public relation - university secretary, physical - nonphysical infrastructure, human resources and student activities. All university's activities have to comply with external government regulation and internal university's strategies and programs. The main and supporting activities chain is illustrated as Fig. 2 below [3].

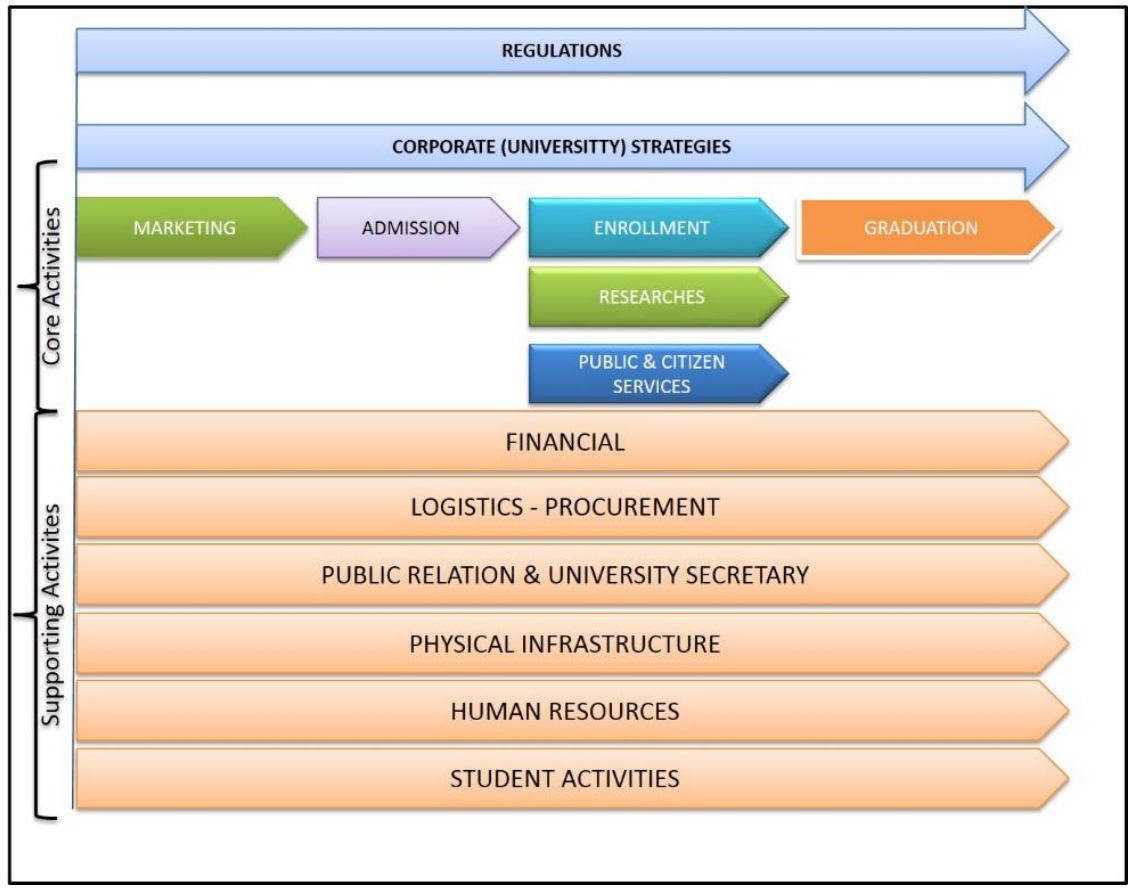

Fig. 2. University's activities chain.

\subsection{User Profile}

IT Division has to serve various users regarding to their levels, needs, and authorities. The internal users consist of students, supporting staff, academic staff (includes lecturer/faculty members), and management level. Based on their unit/division internal, users come from 25 supporting units and 8 faculties which each of them have their own specific function such: lecturer, course and class management, academic finance management, academic administration, physical infrastructure management, student activities management, researches management, public services management, internal control management, learning material management, and career center management. The total internal users have to be served are around 26.000 students and 1.000 academic staff, and 450 nonacademic staff. The external users come from public and student candidates.

\subsection{IS Architecture}

The information system to support all those activities are summarized as an IS architecture. To support the daily activities of the university's staff, student, and executives as well, there are seven main application system includes: marketing system, admission and enrollment system, research activity system, infrastructure/support system, financial system and graduation system. Each of those applications consists of some modules and will manage five kinds of main databases. The users of those application systems will come from both internal and external of campuses. The external users are allowed to access data and information through external portal interfaces. The position and interaction between those applications are 
illustrated as Fig. 2 [3].

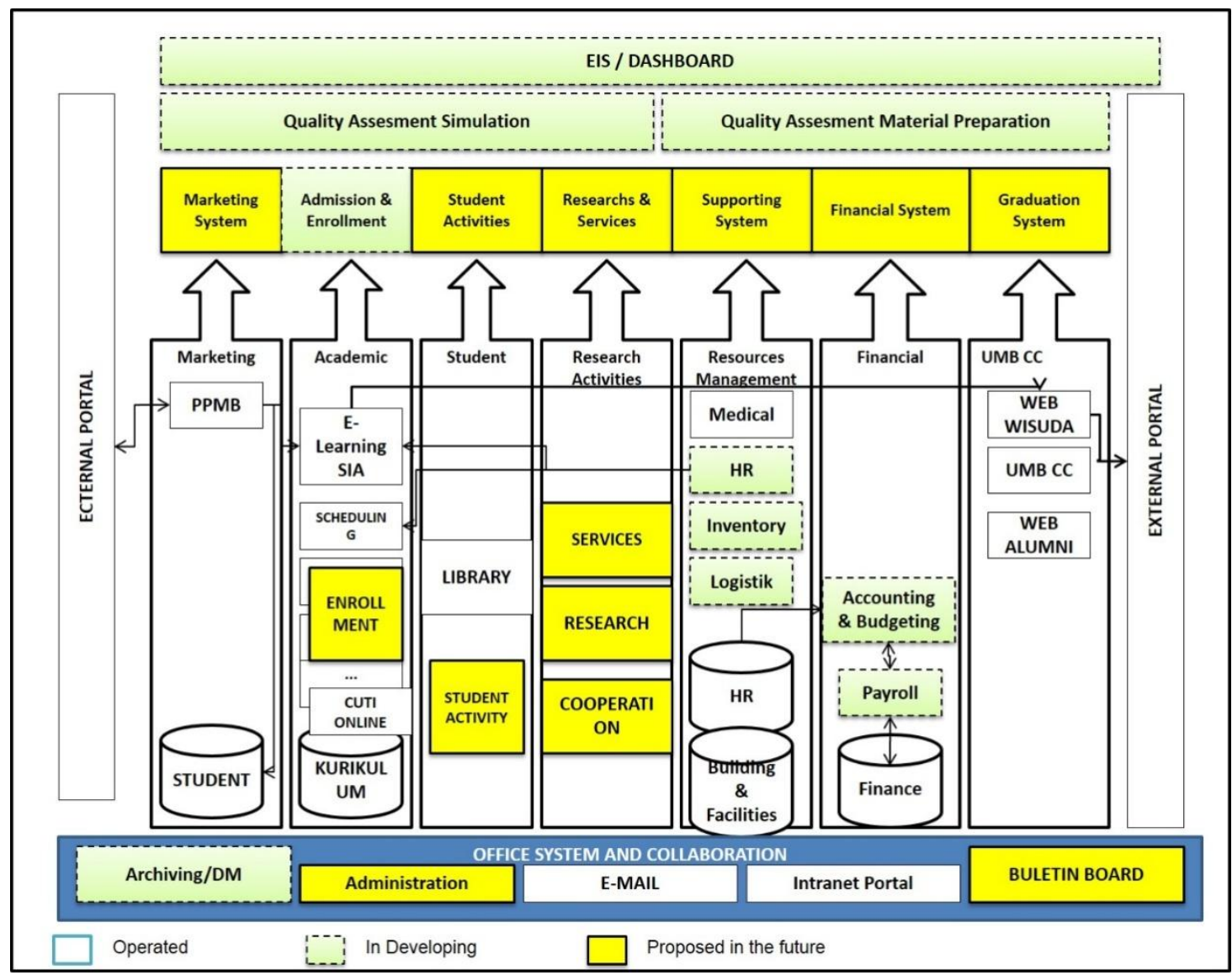

Fig. 3. University's IS architecture.

\section{FLOSS Implementation}

\subsection{Admission-Enrollment System}

The admission - enrollment system is operated to support the admission and enrollment activities in which their functions are specific to the university need and Indonesia education regulation. Therefore there are too difficult to choose any certain FLOSS that can full fill those needs. The choice for this is system is to make a custom developed application. Even though we develop a custom development for this system, the development tools still can be chosen from FLOSS alternatives. And we uses PHP CI framework (http://www.codeigniter.com/) as the development tool.

\subsection{ELearning System}

In university's strategic plan perspective, e-learning is a great way to spread knowledge \& measure the results efficiently (in means of time \& money). The university has provided eLearning services for some of courses since 2007.There are various open source e-learning applications that can be chosen and implemented. Some of those FLOSS e-learning system application are: Openelms (http://www.openelms.org/), Online Learning \& Training/OLAT (http://www.olat.org/), formalms (http://www.formalms.org/), efront (http://www.efrontlearning.net/), moodle (https://moodle.org/), and ILIAS (http://www.ilias.de/).

For the eLearning environment, we select Moodle to be implemented. The consideration to choose Moodle is actually because of this FLOSS has been used by the university since 2007 and this FLOSS is, 
based on experiences, the most popular eLearning application software in Indonesia. In the second implementation of Moodle, we upgrade to Moodle v. 1.7.x to Moodle v.2.9 to improve the performance operation since the previous Moodle version has some limitation, as an example, in handling the concurrent user when the user access forum features. We also apply a server distribution for this eLearning. If in the previous implementation it is only one Moodle server, in this implementation stage we distribute 8 servers so each faculty has their own Moodle server. The distribution model is applied to improve the eLearning availability and reliability, even though it is more difficult to maintain.

\subsection{Archiving/Document Management}

All university's users and division need to store, share and collaborate their documents. The sharing and collaboration of their document will reduce many unnecessary resource spending such: paper, labor, time etc. To accommodate those needs, there are many content management systems can be chosen. Again, there is a plenty DM open source can be used. Some of them can be listed are: alfresco CM (https://www.alfresco.com/), OpenKM (http://www.openkm.com/), kimios (http://www.kimios.com/), OpenDocMan (http://www.opendocman.com/), and Mayan-EDMS (http://www.mayan-edms.com/). These DM FLOSS have their own advantages and drawbacks. For this purpose, we use Alfresco DM community edition. The main consideration why we choose this FLOSS are: the user experiences, the flexibilities in keywords searching and document collaboration. Another FLOSS for document sharing and synchronization we implemented is OwnCloud (https://owncloud.org/). The main advantage of this FLOSS is its capabilities in synchronizing the content in user client to/from university cloud system. The synchronization feature reduces user learning time and user operation time as well.

\subsection{Online Ticketing}

There are so many users with their own characteristics and their own level in information technology literates. Many questions, complaints, or other simple matter think come from those users that has to be handled by university customer care center. The customer care center has to receive, record, distributes and monitor the status of all incoming complaints. To support those complaint management, we implement Osticket (http://osticket.com/) as an online ticket support system. The main consideration why osticket has been chosen since this FLOSS has been explored by one of university students and in it become his final project. So, the university then adopts the student's final exam result. Some other FLOSS online ticketing systems that can be considered are: Otrs (http://www.otrs.com/), Opentickets (http://opentickets.com/), or WebIssues (http://webissues.mimec.org/), Complain Management System(http://www.techzoo.org/), Spport Incident Tracker (http://sitracker.org/),

\subsection{Online Survey}

The university needs feedbacks from their clients (students and their parents) to improve the quality of all services. The subjects of feedback cover a wide range of services from in class activities, the quality of how the lecturer to teach, to the physical infrastructure condition. Since the periods of the survey which is done bi-monthly, the high volume of collected data, and the high quantity of respondent, the University needs semi automation tools to provide the survey and manage the results. For this purpose, we select LimeSurvey (https://www.limesurvey.org/en/). The other online survey FLOSS can be chosen are: SurveyMonkey (www.surveymonkey.com) which offers a popular online hosted survey tool that works well for basic surveys; Opina (www.opinahq.com), an online application that allows us to design and share surveys private or publicly over the Internet; Survey ${ }^{\mathrm{TM}}$ Project (https://survey.codeplex.com/), a free web based survey and (data entry) forms toolkit for processing \& gathering data online.

\subsection{External Portal}


External portals are used as a gateway for information exchange between the University and external users. The university manages one three languages main portal (university website) and more than 35 others portal which are as a representation of each program, faculty and supporting division as well. University main portal (www.mercubuana.ac.id) is developed by utilizing the FLOSS CMS Joomla! (http://www.joomla.org/). Whereas the other more 35 portals are developed with Word press (https://wordpress.org/).

\subsection{Publication System}

Due the regulation complies and the implementation of its vision to become a regional class university research, the university needs to disseminate the publication material such: research papers, student final project reports, conference proceeding paper, etc. There are many alternatives of the Open Source Publication System can be used for this purpose. For the publication system, we choose OJS (Open Journal System) since the completeness of its feature to assist every stage of the refereed publishing process, from submissions through to online publication and indexing. This publication system is developed by PKP (Public Knowledge Project) as a multi-university initiative (http://pkp.sfu.ca/ojs/). Education institutions can assess and choose the publication system which is suitable with their need and constraint. Some of those systems are: ambra (http://www.ambraproject.org/); Annotum, an open-source, open-process, open-access scholarly authoring and publishing platform based on WordPress(http://annotum.org/); DPubS (Digital Publishing System) which is an open-source software system designed to enable the organization, presentation, and delivery of scholarly journals, monographs, conference proceedings, and other common and evolving means of academic discourse (http://dpubs.org/about.html); and E-Journal, a production publishing system which is developed base on Drupal Platform; ePublishing Toolkit, the software package providing tools to help in publishing scientific content on the web (https://dev.livingreviews.org/projects/epubtk/)

\subsection{GAFE}

Google Apps for Education (GAFE) is a suite of productivity application services that Google offers to schools or educational institutions for free. These communication and collaboration apps include Gmail, Calendar, Drive, Docs and Sites. The university signed an agreement with Google local partner to utilize all those applications. In the agreement frameworks, GAFE provide 35.000 account of each 30 GB storage. Beside the Google email system which is on university own domain (@mercubuana.ac.id), university also optimizes the beneficiary of Drive by using it as collaboration tools between students and their supervisor in final projects.

\section{Conclusion}

Based on the practical experiment, the combination of custom (internal) development software and FLOSS is the most reasonable choices to be implemented in some Higher Education Institution, particularly to those institutions which is constrained by budget limitations. However, there are some drawbacks have to be concerned, such as the speed of problem resolution due all problems have to be handled by internal staff and in some case, it may be a certain problem could not be found in internet so the internal staff may be need more time e.g. to analyze the symptoms, to investigate the causes, and to resolve the problem. So for application software which is used to support the high demand process business operation such eLearning or Enrollment, we have to pay more attention in the application solution source assessment. On top of those application selection considerations, the alignment to the corporate / university direction and the capability to full fill user requirements are the first priority. 


\section{Appendix}

This table below shows some screen user interfaces of the implemented FLOSS in the university

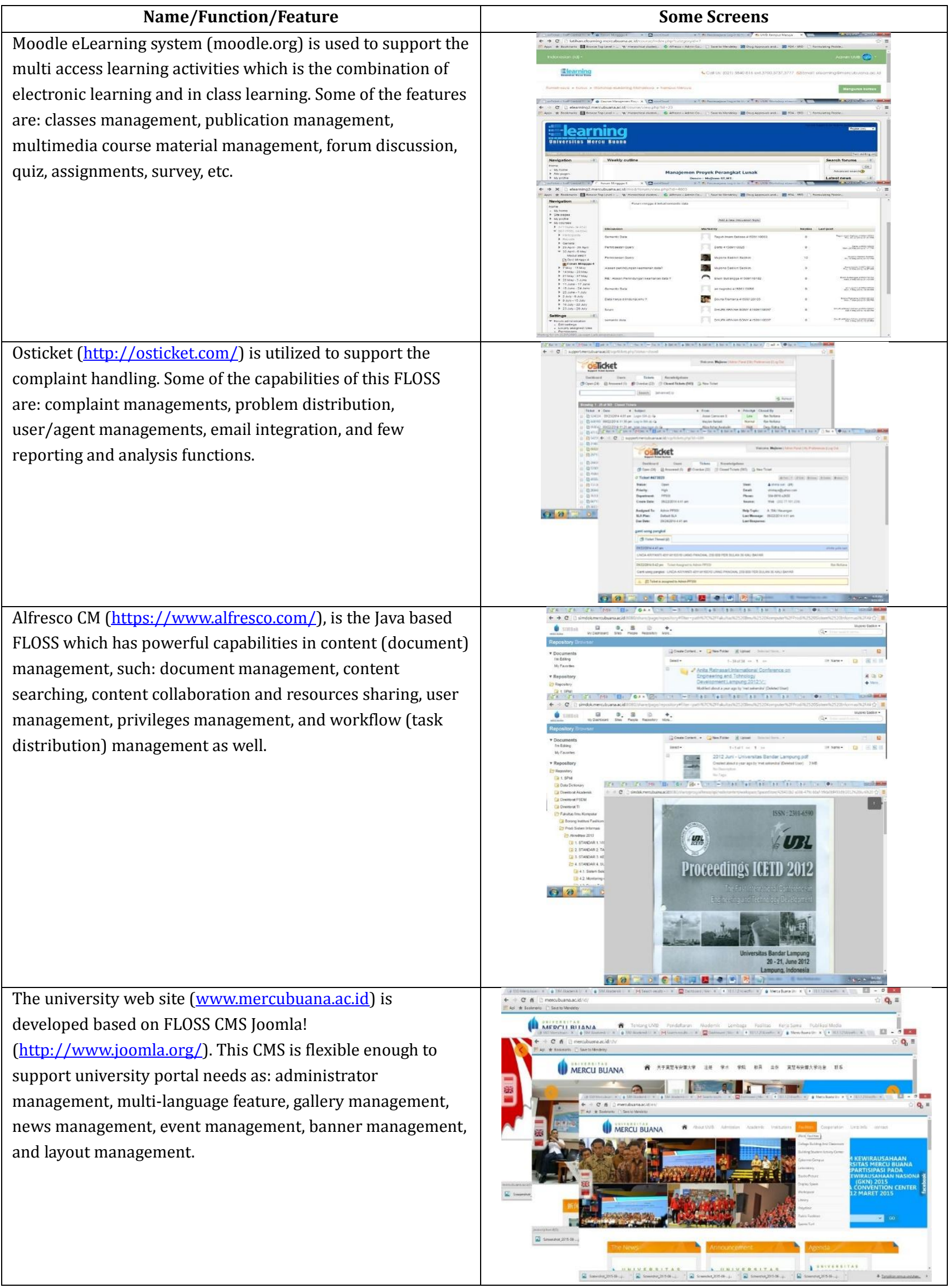




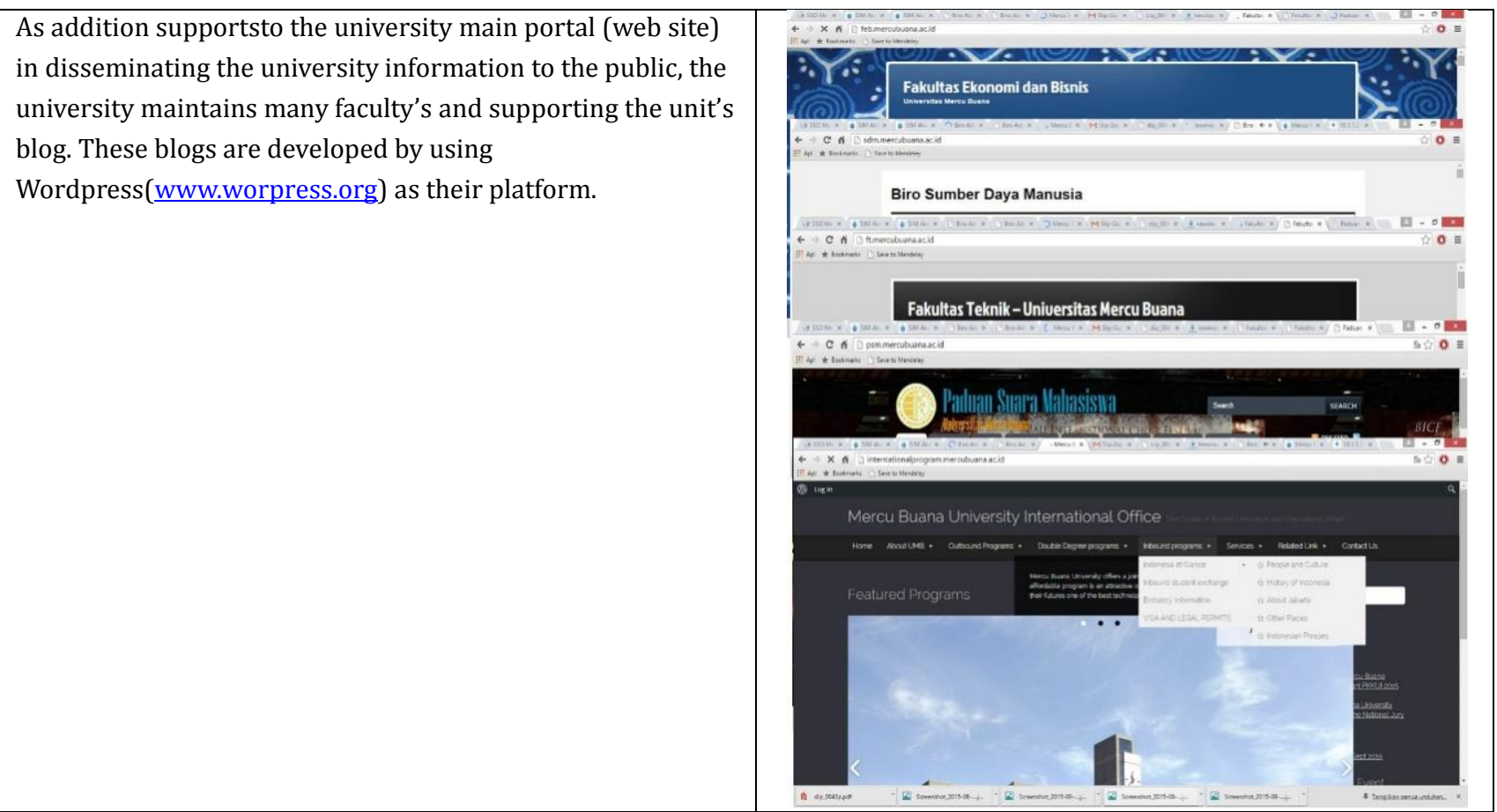

\section{References}

[1] ISACA. (2007). COBIT 4.1. USA: IT Governance Institute.

[2] Sadikin, M., et al. (2014). IT governance self assessment in higher education based on COBIT case study university of mercu buana. J. Adv. Manag. Sci., 2(1), 83-87.

[3] Sarinanto, M. M., et al. (2015). IS strategic plan for higher education based on COBIT assessment: A case study. Int. J. Inf. Educ. Technol., 2(2).

[4] Shaame, A. A. (2014). The adoption of free and open source software in teaching and learning: Case study zanzibar education institutions. Int. J. Manag. Stud. Res., 2(5), 53-59.

[5] Terbuc, M. (2007). Use of free/open source software in e-education. Proceedings of 12th Int. Power Electron. Motion Control Conf. (pp. 1737-1742).

[6] Lipsa, R. S. (2011). Open source software in computer science and IT higher education: A case study. Int. J. Adv. Comput. Sci. Appl., 2(1), 1-6.

[7] Free Software Foundation. (2012). Why educational institutions should use and teach free software. Retrieved from the website: [Online]. Available: http://www.gnu.org/education/edu-why.en.html

[8] Costello, E. (2014). Opening up to open source: Looking at how Moodle was adopted in higher education. Open Learn. J. Open, Distance e-Learning, 28(3), 187-200.

[9] David, P. A., \& Shapiro, J. S. (2007). Higher education institutions and the global role of free / libre and open source software a report on findings from the flossw orld survey by. London.

[10] Cuts, B., \& Computing, A. (2004). Tech Budgets Get Some Relief Cautious Support for Open Source Applications. Encino, CA.

[11] Abel ,R. J. (2006). Best practices in open source in higher education study: The state of open source software. Lake Mary. FL.

[12] Arslan,.M. O. (2014). Free and open source software as a public good: Implications for. Eur. J. Res. Educ.,. 2014(2), 158-165.

[13] Coll, H. D., et al. (2008). Free software and open source applications in higher education. Proceedings of International Conference on Engineeriing Education (pp. 325-330). 
[14] Zymaris, C., \& Patten, B. (2008). Free Software for Schools. Victoria: Open Source Victoria.

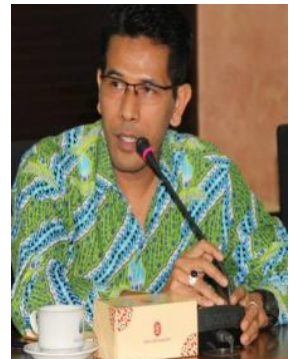

Mujiono Sadikin was born in Magetan, East Java, Indonesia on December 6, 1970. He holds a bachelor degree in informatics major of Bandung Institute of Technology, Bandung, Indonesia. His master degree is also held in the same field, the same institution as well. Currently he is a doctoral student in computer science, University of Indonesia. He also holds CISA certification since 2011. He has many experiences in IT governance, IT stretegic planning, and information system solution projects. Since 2012 he led the University of Mercu Buana IT Directorate as the director. 